\title{
Minireview
}

\section{The Roles of Xenobiotic Receptors: Beyond Chemical Disposition}

\author{
Bryan Mackowiak, Jessica Hodge, Sydney Stern, and Hongbing Wang \\ Department of Pharmaceutical Sciences, University of Maryland School of Pharmacy, Baltimore, Maryland
}

Received February 16, 2018; accepted May 7, 2018

\section{ABSTRACT}

Over the past 20 years, the ability of the xenobiotic receptors to coordinate an array of drug-metabolizing enzymes and transporters in response to endogenous and exogenous stimuli has been extensively characterized and well documented. The constitutive androstane receptor (CAR) and the pregnane $X$ receptor (PXR) are the xenobiotic receptors that have received the most attention since they regulate the expression of numerous proteins important to drug metabolism and clearance and formulate a central defensive mechanism to protect the body against xenobiotic challenges.

However, accumulating evidence has shown that these xenobiotic sensors also control many cellular processes outside of their traditional realms of xenobiotic metabolism and disposition, including physiologic and/or pathophysiologic responses in energy homeostasis, cell proliferation, inflammation, tissue injury and repair, immune response, and cancer development. This review will highlight recent advances in studying the noncanonical functions of xenobiotic receptors with a particular focus placed on the roles of CAR and PXR in energy homeostasis and cancer development.

\section{Introduction}

Nuclear receptors (NRs) are transcription factors that are activated by both endogenous and exogenous ligands, leading to the initiation of biologic responses through alteration of target gene transcription (Forman and Evans, 1995). Utilizing classic endocrinology approaches, a number of steroid hormone receptors such as the estrogen, androgen, glucocorticoid, and progesterone receptors were initially isolated (Jensen and Jacobson, 1960; Hollenberg et al., 1985; Misrahi et al., 1987; Lubahn et al., 1988). Containing relatively compact ligandbinding domains, these receptors are responsive primarily to endogenous steroid hormones with high binding sensitivity often at nanomolar concentration ranges (Nagy and Schwabe, 2004; Sonoda et al., 2008). Different from these traditional endocrine receptors, receptors that respond to a diverse array of foreign compounds including environmental chemicals and clinically used drugs, while lacking physiologically relevant endogenous ligands, are termed xenobiotic receptors (XRs). These include, but are not limited to, the constitutive androstane receptor [(CAR); NR1i3], the pregnane $X$ receptor [(PXR); NR1i2], the aryl hydrocarbon receptor (although it is not categorized in the NR family), and the peroxisome proliferator-activated receptors (Issemann and Green, 1990; Dreyer et al., 1992; Kliewer et al., 1998; Moore et al., 2000; Denison and Nagy, 2003; Wang and LeCluyse, 2003). Notably,

This work was supported by the National Institutes of Health National Institute of General Medical Sciences [Grants GM107058 and GM121550].

The authors state no conflict of interest and have received no payment in preparation of this manuscript.

https://doi.org/10.1124/dmd.118.081042.
XRs have bulky and less conserved ligand-binding domain, which allow them to accommodate a structurally diverse library of ligands (Ekins et al., 2009). For instance, PXR, the primary regulator of CYP3A4 transcription, probably has the largest ligand-binding pocket in the entire NR superfamily, which enables the fitting of large and structurally diverse ligands (Watkins et al., 2001). Indeed, the broad spectrum of ligands that can activate PXR matches the substrate diversity of CYP3A4, the most abundant human liver cytochrome P450 enzyme that is responsible for the metabolism of $30 \%-50 \%$ of clinically used drugs (Kumar and Surapaneni, 2001; Zanger et al., 2008). In response to xenobiotic challenges, XRs coordinate a defensive network by regulating the transcription of genes encoding drug-metabolizing enzymes (DMEs) and transporters, which facilitate the breakdown and excretion of foreign substances from the body (Handschin and Meyer, 2003; Qatanani and Moore, 2005; Wang et al., 2012). Consistent with their metabolism/detoxification roles, the majority of XRs are highly expressed in the liver and intestines, which are the primary organs responsible for metabolism and clearance of exogenous chemicals. Typically, XRs are sequestered in the cytoplasm and translocate to the nucleus of primary hepatocytes in vitro and intact liver in vivo, upon agonistic stimulation (Ikuta et al., 1998; Kawamoto et al., 1999; Kawana et al., 2003; Li et al., 2009). Once inside the nucleus, XRs heterodimerize with their protein partners and bind to specific response elements located upstream of their target genes to trigger transcription. While this process is beneficial to rid toxic compounds from the body in general, induction of DMEs and transporters by XR activation in response to pharmaceuticals is known to cause unexpected drugdrug interactions that can lead to severe toxicity and/or loss of

ABBREVIATIONS: CAR, constitutive androstane receptor; DME, drug-metabolizing enzyme; EGF, epidermal growth factor; G6Pase, glucose-6phosphatase; HCC, hepatocellular carcinoma; HFD, high-fat diet; miRNA, microRNA; NR, nuclear receptor; PB, phenobarbital; PCN, pregnenolone $16 \alpha$-carbonitrile; PEPCK, phosphoenolpyruvate carboxykinase; PGC1 $\alpha$, peroxisome proliferator-activated receptor gamma coactivator-1 $\alpha$; PXR, pregnane X receptor; RXR, retinoid X receptor; SGK2, serum/glucocorticoid regulated kinase 2; TCPOBOP, 1,4-bis[2-(3,5-dichloropyridyloxy)] benzene; T3, triiodothyronine; T4, tetraiodothyronine; WT, wild type; XR, xenobiotic receptor. 
therapeutic efficacy (Honkakoski et al., 2003; Köhle and Bock, 2009; Tolson and Wang, 2010).

As xenobiotic sensors, CAR and PXR have been extensively studied over the past 20 years, due mostly to their broad and critical roles in governing the inductive expression of major DMEs such as phase I cytochrome P450 enzymes (i.e., CYP2B6, CYP2Cs, and CYP3A4) and phase II UDP-glucuronosyltransferases (i.e., UGT1A1 and UGT1A9) and sulfotransferases (i.e., SULT1A1, and SULT1D1), as well as drug transport proteins including organic anion-transporting polypeptides (uptake) and multidrug resistance proteins (efflux) (Xie et al., 2000; Timsit and Negishi, 2007; Köhle and Bock, 2009; Banerjee et al., 2015). Research thus far has clearly established that these receptors form the backbone of xenobiotic response, especially in the liver and intestines, by upregulating the expression of an overlapping yet distinctive array of important DMEs and transporters. Of note, although the effects of XRs as xenobiotic sensors dictating chemical metabolism and disposition have been extensively investigated, accumulating evidence reveals that XRs can also function as signaling molecules that modulate physiologic and pathophysiologic functions including energy metabolism, insulin signaling, inflammation, immune response, cell proliferation, apoptosis, autophagy, and cancer development (Gao and Xie, 2012; Banerjee et al., 2015; Yan et al., 2015; De Mattia et al., 2016; Kazantseva et al., 2016; Gutiérrez-Vázquez and Quintana, 2018; Roman et al., 2018). This review aims to highlight the recent advances in our understanding of the nontraditional endobiotic roles of CAR and PXR with particular emphases on energy homeostasis and cancer development.

\section{Constitutive Androstane Receptor}

Initial characterization of CAR revealed that it was an orphan NR that binds DNA as a heterodimer with the retinoid $X$ receptor (RXR) without the involvement of any identified ligand (Baes et al., 1994). The high basal activity of CAR in immortalized liver cells, along with the early identification of the steroid ligands androstanol and androstenol as antagonists of CAR (although at concentrations much higher than the physiologic levels) gave rise to its current established name (Baes et al., 1994; Forman et al., 1998). Orthologous mouse and rat $C A R$ genes were cloned in the years following the isolation of human CAR, and the murine proteins were likewise found to heterodimerize with RXR and to display similar constitutive activity (Choi et al., 1997; Yoshinari et al., 2001). Our recognition of the importance of CAR in xenobiotic metabolism began with exploration into the enzyme-inducing effects of phenobarbital (PB), a powerful antiepileptic drug. The PB-provoked expression of $C Y P 2 B$ genes was found to involve a DNA response element accordingly denominated the PB-responsive enhancer module in the $C Y P 2 B$ gene promoter regions, and CAR was established as the key NR that regulates the inductive expression of CYP2B by numerous PB-like chemicals (Trottier et al., 1995; Park et al., 1996; Honkakoski and Negishi, 1997; Honkakoski et al., 1998; Sueyoshi et al., 1999; Wei et al., 2000; Staudinger et al., 2013).

The mechanisms by which CAR is activated and deactivated along with its heterodimerization with RXR have been well elucidated. In primary hepatocytes, CAR remains cytosolic prior to activation either through direct interaction with a ligand or via indirect signaling pathways (Kawamoto et al., 1999; Kanno et al., 2005; Li and Wang, 2010). Inactive cytoplasmic CAR, phosphorylated at threonine 38 of the DNA-binding domain, gains activity through dephosphorylation of this residue via protein phosphatase $2 \mathrm{~A}$, which is recruited to the CAR protein complex by dephosphorylated RACK1 (Mutoh et al., 2009, 2013). This activation could be antagonized by extracellular signalregulated kinase $1 / 2$ following the binding of epidermal growth factor (EGF) to its EGF membrane receptor (Koike et al., 2007; Osabe and
Negishi, 2011) or via metformin-mediated activation of the AMPactivated protein kinase (Yang et al., 2014). Most recently, Shizu et al. (2017) described a conversion between CAR monomer and homodimer states within the hepatocellular cytoplasm, where cytosolic CAR homodimerizes when cells are treated with EGF, and the complex dissociates when cells are treated with erlotinib, a tyrosine kinase inhibitor of the EGF receptor. This report further demonstrated that RACK1 binds CAR in the monomer state but not when CAR exists as a homodimer, since the homodimer interaction interface buries the requisite binding site. Another recent study suggested, however, that rather than taking place within the nucleus, heterodimerization of both CAR and PXR with RXR occurs within the cytoplasm. Dash and colleagues reported that nuclear entry of CAR-RXR and PXR-RXR heterodimers is dependent on the intact nuclear localization signal of at least one of the partners and is strongly influenced by the RXR nuclear localization signal (Zelko et al., 2001; Dash et al., 2017). Interestingly, these results contrast with interaction energy-based predictions from the aforementioned study, which would suggest that CAR-RXR heterodimerization would be favored over (and would thus preclude) CAR homodimerization in the cytoplasm if RXR were present. Although the precise cytoplasmic conditions and mechanisms of CAR dimerization remain elusive, both direct and indirect activators translocate cytosolic CAR to the nucleus as the essential first step of activation. Hitherto, numerous xenobiotics have been identified as either direct or indirect activators of CAR, which are able to trigger complicated cellular responses in a CAR-dependent manner.

Initial and extensive investigations have focused on the role of CAR in regulating DMEs and transporters that protectively dispose of exogenous compounds such as toxic environmental substances and drugs (Yamamoto et al., 2003; Qatanani and Moore, 2005). To date, both the molecular mechanisms and biologic consequences of CARmediated xenobiotic metabolism and disposition have been well documented and thus will not be the focus of this review. As insight into the homeostatic effects of CAR deepens, an expanding body of literature has emerged exploring the endogenous roles of CAR beyond xenobiotic disposition. It has long been known that PB (a prototypical CAR activator) improves insulin sensitivity and decreases blood glucose levels in patients with type 2 diabetes (Lahtela et al., 1985). Metabolic benefits were observed in wild-type (WT) but not $\mathrm{CAR}^{-1-}$ mice treated with 1,4-bis[2-(3,5-dichloropyridyloxy)] benzene (TCPOBOP), a potent mouse CAR agonist (Dong et al., 2009; Gao et al., 2009). Additional studies have shown that CAR is involved in liver regeneration, inflammation, hepatocarcinogenesis, and renal ischemia-reperfusioninduced kidney injury (Huang et al., 2005; Tschuor et al., 2016; Tanner et al., 2018). Here, we will concentrate on the recent findings regarding the role of CAR in energy homeostasis and cell proliferation. It is provocative that modulation of CAR activity in these domains may have therapeutic potential in managing diseases such as obesity, type 2 diabetes, and cancers.

CAR and Energy Homeostasis. The involvement of CAR in energy homeostasis was first recognized over a decade ago when CAR activation by $\mathrm{PB}$ in mice resulted in downregulation of genes associated with gluconeogenesis and fatty acid synthesis (Ueda et al., 2002). Subsequently, growing evidence supporting a role of CAR in energy homeostasis and metabolic disorders has promoted investigation into the broad function of CAR beyond xenobiotic disposition. In 2004, Maglich and coworkers reported that under caloric restriction and fasting, CAR mediated a compensatory response to limit energy expenditure in mice by downregulation of serum levels of triiodothyronine (T3) and tetraiodothyronine (T4), two major thyroid hormones that control the basal metabolic rate (Maglich et al., 2004). Notably, fasting stimulated a CAR-dependent induction of sult1a1, sult2a1, and ugt1a1, which are 
important for the metabolic breakdown of $\mathrm{T} 3$ and $\mathrm{T} 4$. In $\mathrm{CAR}^{-\prime-}$ mice, however, fasting failed to induce the expression of these enzymes and the serum concentrations of $\mathrm{T} 3$ and $\mathrm{T} 4$ remained high, which led to more weight loss under caloric restriction than in WT mice (Maglich et al., 2004). Interestingly, in another report, while the authors did not observe fasting-stimulated CAR activation, the study demonstrated that CAR is required for a $\mathrm{PB}$-induced decrease in $\mathrm{T} 3$ and $\mathrm{T} 4$ levels in the serum; treatment with $\mathrm{PB}$ or TCPOBOP induced the expression of sulfotransferases and UDP-glucuronosyltransferases that are important for T3 and T4 metabolism in WT but not $\mathrm{CAR}^{-/-}$mice (Qatanani et al., 2005). Given that decreased basal energy expenditure represents a major barrier for obese individuals trying to lose weight, antagonism of human CAR may potentially benefit patients under a weight loss program, if the aorementioned findings hold true in humans. In contrast to these findings, two research groups independently showed that activation of CAR by TCPOBOP markedly ameliorated symptoms of obesity, diabetes, and fatty liver induced by high-fat diet (HFD) in WT mice, while such effects were not observed in TCPOBOP-treated $\mathrm{CAR}^{-1-}$ mice (Dong et al., 2009; Gao et al., 2009). Further gene expression and biochemical analyses have revealed that the metabolic benefits of CAR activation may involve the suppression of glucose and lipid production, the inhibition of triglyceride and very-low-density lipoprotein export, and induction of $\beta$-oxidation and energy expenditure.

Mechanistically, CAR-mediated energy homeostasis appears to be involved in a combined repression of an array of genes associated with gluconeogenesis, fatty acid synthesis, and energy expenditure such as phosphoenolpyruvate carboxykinase (PEPCK), glucose-6-phosphatase (G6Pase), fatty acid synthase, and stearoyl-CoA desaturase-1 (Yu et al., 2016). This downregulation is involved in the prevention of the FOXO1 transcription factor from interacting with insulin response element binding sites located upstream of genes such as PEPCK1, G6Pase, and insulin-like growth factor-binding protein 1 (Kodama et al., 2004). Through direct interaction between CAR and FOXO1 activated CAR acting as a corepressor downregulates FOXO1-mediated transcription of gluconeogenic genes. Binding of CAR to the direct repeat 1 site in the PEPCK promoter in place of hepatic nuclear factor- $4 \alpha$ (a key hepatic factor crucial for the expression of bile acid synthesis and gluconeogenic genes) has also been reported as a means of metabolic suppression by CAR (Miao et al., 2006). The peroxisome proliferator-activated receptor gamma coactivator- $1 \alpha(\mathrm{PGC} 1 \alpha)$ is another key transcriptional coactivator that governs energy metabolism by regulating the expression of PEPCK and G6Pase (Herzig et al., 2001). Gao et al. (2015) recently demonstrated that when bound by its ligand CAR alters the subcellular localization and degradation of PGC $1 \alpha$ through direct CAR-PGC $1 \alpha$ interaction, by which the CAR-PGC1 $\alpha$ complex is coredistributed to the promyelocytic leukemia protein-nuclear bodies, where activated CAR facilitates the ubiquitination and degradation of PGC $1 \alpha$ by recruiting Cullin $1 \mathrm{E} 3$ ligase. This finding suggests that in addition to transcriptional repression, post-translational modification of protein stability may also contribute to CAR-mediated suppression of hepatic gluconeogenesis.

In contrast with the relatively consistent repression of gluconeogenesis by CAR activation, more conflicting experimental results have been generated regarding the role of CAR in the regulation of lipogenesis. Activation of CAR in mice has been shown to mitigate hepatic steatosis, increase glucose tolerance and insulin sensitivity, and alleviate or prevent obesity in diabetic mouse models (Dong et al., 2009; Gao et al., 2009). CAR-mediated antilipogenic effects were also observed in hyperlipidemic HepG2 cell cultures treated with evodia alkaloids (Yu et al., 2016). Furthermore, the hormone irisin was recently identified as a direct target of CAR and protects HFD-induced obese mice through the CAR-irisin axis (Mo et al., 2016). Results of this study corroborated prior research on the effects of the hormone and demonstrated that hepatic expression of irisin suppresses lipogenesis (Zhang et al., 2013; Polyzos et al., 2014; Mo et al., 2016).

On the other hand, the majority of current studies were carried out under metabolic/nutritional challenges such as HFD-feed or caloric restriction. Interestingly, Marmugi et al. (2016) reported that treatment with TCPOBOP provoked the expression of lipogenic and glycolytic genes and increased lipid levels in a CAR-dependent manner in the livers of healthy mice under physiologic conditions. A novel CAR target gene within the lipogenic category, Pnpla3 (Romeo et al., 2008; Smagris et al., 2015), was identified that may contribute to the observed fatty liver phenotype. A separate study demonstrated that the high serum triglyceride level of leptin-function deficient $(o b / o b)$ mice was completely normalized when crossed onto a $\mathrm{CAR}^{-1-}$ background (Maglich et al., 2009). Notably, when maintained on a normal diet, treatment with TCPOBOP $(0.3 \mathrm{mg} / \mathrm{kg}$ ip once daily for 14 days $)$ resulted in a $50 \%$ increase in serum triglycerides in WT but not $\mathrm{CAR}^{-1-}$ mice. This is in stark contrast to the Gao et al. (2009) observation, where TCPOBOP $(0.5 \mathrm{mg} / \mathrm{kg}$ i.p. once per week for 8 weeks) reduced serum triglyceride from 230 to $132 \mathrm{mg} / \mathrm{dl}$ in WT mice fed with a HFD regimen. It is possible that HFD-induced nutritional stress contributes significantly to the contradictory results in these studies, although factors such as the TCPOBOP treatment regimen and the genetic background of the mice used cannot be excluded. Additionally, the inherited species differences between human and mouse CAR may further complicate the dispute. In primary and immortalized human hepatocytes, activation of CAR promotes the expression of lipogenic genes such as stearoyl-CoA desaturase-1 and Pnpla3 (Marmugi et al., 2016). Another study using human primary hepatocytes found that CAR activation, while inhibiting gluconeogenesis, did not affect the expression of genes associated with hepatic lipogenesis (Lynch et al., 2014). Collectively, a correlation between CAR and energy homeostasis has been firmly established (Fig. 1). Numerous studies have demonstrated that activation or deactivation of CAR can disturb the balance of energy metabolism/ expenditure. However, the exact role of CAR in metabolic disorders continues to be uncertain or even controversial. Information pertaining to humans in particular is limited.

CAR in Cell Proliferation and Cancer. The effect of CAR activation on mitogenesis has been the subject of intense inquiry since the discovery that CAR is responsible for PB- and TCPOBOP-induced liver hypertrophic and hyperplastic responses in mice (Wei et al., 2000). This topic is intriguing from two standpoints: whereas a hyperplastic response might lead to the development of cancer in certain circumstances, a regenerative response following severe tissue injury is often critical to survival. The essential role of CAR in PB- and TCPOBOPmediated tumor promotion was initially established by using $\mathrm{CAR}^{-1-}$ and WT mice, in that activation of CAR is associated with both induction of DNA replication and suppression of apoptosis (Yamamoto et al., 2004; Huang et al., 2005; Phillips et al., 2007). Subsequent studies have further confirmed that a class of rodent CAR activators exhibits tumor-promoting activities in a CAR-dependent manner (Maeda et al., 2015; Tamura et al., 2015, 2016; Okuda et al., 2017; Wang et al., 2017). Although the underlying molecular mechanisms by which CAR stimulates tumor promotion are not fully elucidated, accumulating evidence reveals that activation of CAR alters the expression of GADD45 $\beta$, mdm2, TUBA8, FAM84A, and c-Myc, which are all closely correlated with cell proliferation and oncogenic signaling (Huang et al., 2005; Blanco-Bose et al., 2008; Yamamoto et al., 2010; Kamino et al., 2011a,b).

Recently, Dong et al. (2015) studied the relationship between mouse CAR activation and the $\mathrm{Wnt} / \beta$-catenin pathway in the development of liver tumors. Although no evidence was found of direct interaction 


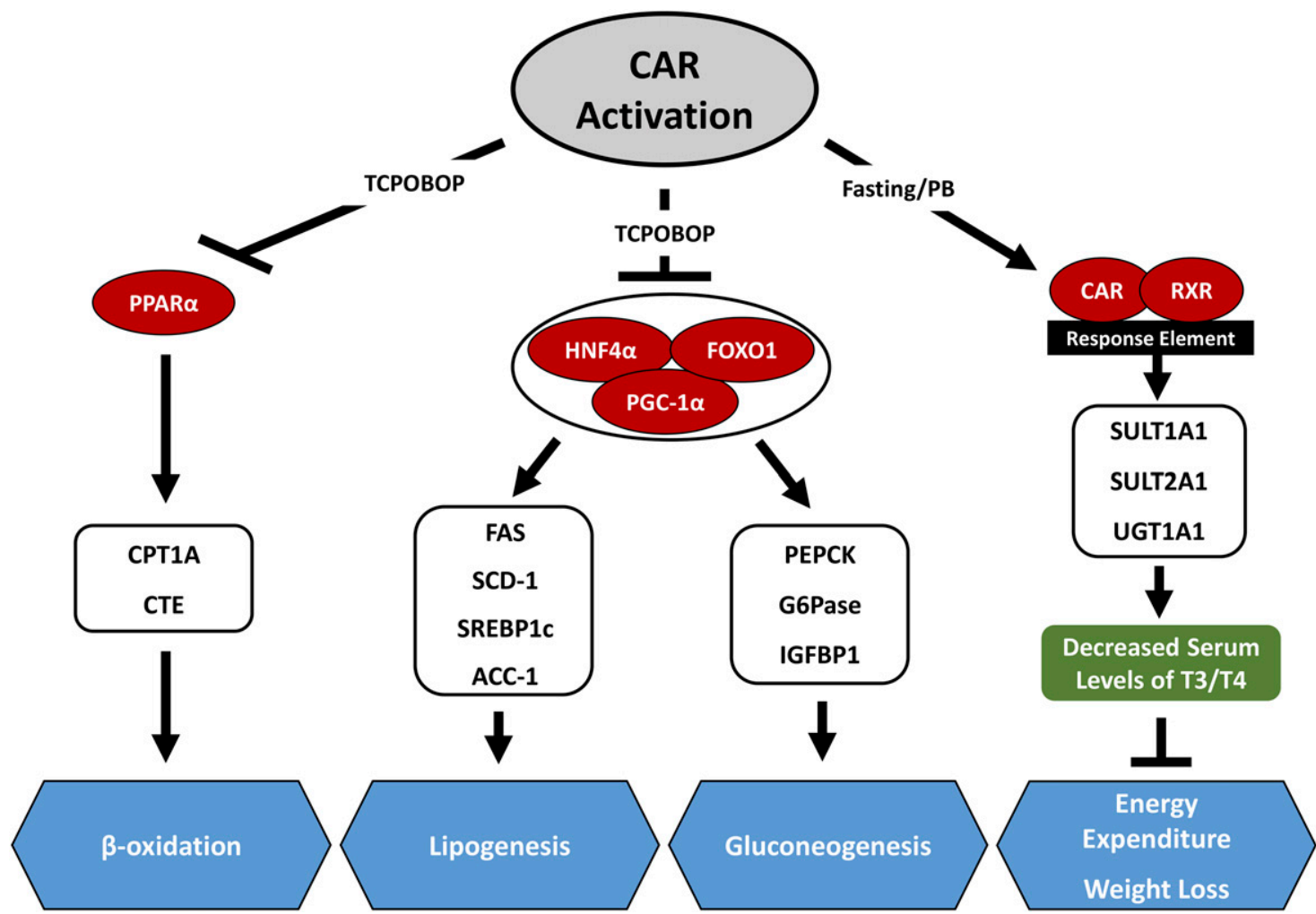

Fig. 1. Effects of CAR activation on energy homeostasis. Schematic illustration of how CAR activation affects energy metabolism and balance. Activation of CAR by agonists or caloric restriction leads to the up- and downregulation of a cluster of genes associated with gluconeogenesis, lipogenesis, $\beta$-oxidation, and energy expenditure by altering the activities of specific transcription factors such as peroxisome proliferator-activated receptor $\alpha$ (PPAR $\alpha$ ), hepatic nuclear factor- $4 \alpha$ (HNF4 $\alpha$ ), FOXO1, and PGCl $\alpha$.

between CAR and $\beta$-catenin at the transcriptional level, the results of the study showed that CAR activation prevented the senescence that would otherwise be triggered by $\mathrm{Wnt} / \beta$-catenin activation over time and that the two act synergistically to promote liver cell proliferation and hepatocellular carcinoma (HCC) development. However, another study by Braeuning et al. (2016) found that in $\mathrm{Apc}^{-1-}$ mice (where activated protein $\mathrm{C}$ forms part of the protein complex that is essential to normal degradation of $\beta$-catenin), treatment with $\mathrm{PB}$ did not result in a persistent proliferative advantage. $\mathrm{PB}$ was shown to promote adenoma but inhibit carcinoma in liver cells of $\mathrm{Apc}^{-1-}$ mice. Although mechanisms other than those directly involving CAR in the inhibition of HCC were not ruled out, the study points to the paradoxical properties of $\mathrm{PB}$ in tumor promotion and the need for additional investigation. Most recently, Tschuor et al. (2016) studied the regenerative effects of CAR in mouse liver following extreme (91\% of liver volume resected), extended ( $86 \%$ resected), and standard (70\% resected) hepatectomy. Marked impairment in mouse CAR activation following extended hepatectomy was observed, and liver dysfunction and lack of regeneration corresponded with similar phenomena in $\mathrm{CAR}^{-1-}$ mice that had undergone standard hepatectomy. Following administration of the mouse CAR activator TCPOBOP, survival was significantly improved in WT but not $\mathrm{CAR}^{-/-}$ mice. Since a regenerative response is essential to avoid potential liver failure after significant resection in the setting of tumor invasion or following transplantation with reduced-size liver grafts, therapeutic human CAR intervention may play a role in recovery from compromising liver surgery in the future (Clavien et al., 2012; Tschuor et al., 2016).

MicroRNAs (miRNAs) are short noncoding RNAs that play important roles in the post-transcriptional regulation of genes associated with various diseases, including HCC. miR-122, the most abundant hepatic
miRNA, has been established as a tumor suppressive miRNA in the liver (Coulouarn et al., 2009). Of note, the expression of miR-122 was markedly downregulated in $\mathrm{C} 3 \mathrm{H} / \mathrm{HeN}$ mice in vivo and HepG2 cells in vitro treated with PB (Shizu et al., 2012). Kazantseva et al. (2015) further demonstrated that activated CAR represses the expression of miR-122 through direct competition with HNF4a for binding to the DR1 response element located upstream of the pri-miR-122 promoter, a mechanism by which CAR suppresses a number of other HNF4a target genes. Using deep sequencing approaches, Hao et al. (2016) profiled the global miRNA expression patterns in livers from C57BL/6J mice treated with TCPOBOP or dimethylsulfoxide as the vehicle control. Among the 51 miRNAs significantly altered by TCPOBOP treatment in this study, known oncogenic miRNAs, such as miR-148a, miR-let-7f, and miR671 , were upregulated, supporting the idea that CAR may modulate a network of miRNAs in facilitating mouse hepatocyte proliferation. In addition to CAR-mediated regulation of miRNA expression, the expression of CAR itself can also be repressed by miRNA such as miR-137, which was observed in cellular models of hepatocellular and colon cancers (Takwi et al., 2014). More in-depth analysis of the rather comprehensive roles of miRNA in CAR-dependent hepatocarcinogenesis is warranted.

Another mechanism by which CAR may influence cancer development is through its involvement in circadian rhythm homeostasis. CAR expression has been shown to elevate during the night in mice, corresponding to their regular feeding patterns (Gachon et al., 2006). More recent studies have expanded on the link between CAR activity and circadian rhythms. For example, PER2 has been found to directly interact with CAR, with implications that have yet to be explored (Martini et al., 2017). Additionally, a shifted feeding schedule in rats (i.e., daytime rather than nighttime feeding) likewise caused a shift in 
CAR expression (de Vries et al., 2017). Significant disruption in circadian rhythms over time, in turn, has recently been demonstrated by Kettner et al. (2016) to provoke nonalcoholic fatty liver disease, fibrosis, and HCC in correlation with elevated bile acid and CAR levels in mice. Increased levels of CAR were found to be related to disruption in sympathetic nervous system signaling and peripheral tissue clock activity.

Compared with what we have learned from rodent animals with regard to the role of CAR in cancer development, the function of CAR in human hepatocarcinogenesis continues to be controversial, and in-depth studies are limited. Indeed, although PB represents a prototypical CAR activator and known nongenotoxic carcinogen that promotes liver cancer in rodents, PB-induced replicative DNA synthesis and hepatocellular proliferation in rodents were not observed in either cultured human hepatocytes in vitro or in chimeric mice with humanized liver in vivo (Elcombe et al., 2014; Yamada et al., 2014; Soldatow et al., 2016; Haines et al., 2018). Moreover, epidemiologic studies have shown that PB and a number of PB-like nongenotoxic rodent carcinogens do not increase the incidence of liver tumors in humans, even after long therapeutic applications at doses producing plasma concentrations challenging those that are carcinogenic in rodents (Braeuning, 2014; La Vecchia and Negri, 2014). When the human CAR transcriptome was recently analyzed using WT and $\mathrm{CAR}^{-1-}$ HepaRG cells, many cell proliferation-associated genes were upregulated in $\mathrm{CAR}^{-/-}$but not WT cells (Li et al., 2015a). Additionally, in human brain tumor stem cells, activation of CAR by 6-(4-chlorophenyl)imidazo [2,1-beta][1,3]thiazole-5-carbaldehyde- $O$-(3,4-dichlorobenzyl)oxime was associated with cell cycle arrest and enhanced apoptosis both in vitro and in an in vivo xenograft model (Chakraborty et al., 2011). Collectively, these studies raise significant concerns regarding direct extrapolation of findings from rodents to humans, particularly with regard to the role of CAR in cancer development.

Additional Endobiotic Functions of CAR. In addition to the roles discussed previously, CAR has important endobiotic metabolism functions, including its regulation of bilirubin and bile acid processing genes (Huang et al., 2003; Wagner et al., 2005). A 2017 study addressing a potential role of CAR in prevention of cholesterol gallstone disease found that CAR activation by TCPOBOP in lithogenic diet-fed mice prevented the development of cholesterol gallstones (Cheng et al., 2017). Furthermore, although primarily studied in the liver, CAR has also been investigated in other organs, such as brain and intestine. Boussadia et al. (2016) recently explored the role of CAR in pathophysiologic brain processes and found that $\mathrm{CAR}^{-1-}$ mice displayed inferior memory function and greater levels of anxiety, as indicated by behavioral tests, when compared with WT mice. Electroencephalographic changes in $\mathrm{CAR}^{-1-}$ mice were found to correlate with memory impairment, and microvessels exhibited morphologic changes that were suggestive of inflammatory processes. Additionally, when a seizure-inducing neurotoxin was peripherally administered, $\mathrm{CAR}^{-1-}$ mice experienced quicker-onset and more prolonged seizure episodes than did WT mice, reinforcing the increased vascular permeability suggested by other experimental results (Boussadia et al., 2016). The effects of CAR in intestinal tissue were also recently studied by Hudson et al. (2017). The expression of CAR in inflamed, nonulcerated intestinal mucosal tissue from patients with ulcerative colitis and Crohn's disease was found to be markedly reduced when compared with corresponding tissue from healthy donors, results that were duplicated in intestinal mucosal samples from mice with chemically induced inflammation (Hudson et al., 2017). When intestinal tissue was collected from $\mathrm{CAR}^{-1-}$ mice after a week's recovery time following chemically induced mucosal damage, mucosal tissue had failed to recover to the extent observed in WT mice in terms of both damage and inflammation.
CAR activation by 6-(4-chlorophenyl)imidazo [2,1-beta][1,3]thiazole5 -carbaldehyde- $O$-(3,4-dichlorobenzyl)oxime in Caco-2 intestinal epithelial cells was found to increase the migratory distance of these cells, an effect that was correlated with increased p38 mitogen-activated protein kinase activation, and to aid wound closure while having no effect on cell proliferation. Most recently, Choi et al. (2018) demonstrated interesting kidney-liver crosstalk in response to acute kidney injury, where TCPOBOP alleviates serum interleukin 6 elevation induced by renal ischemia/reperfusion in a CAR-dependent manner.

Taken together, these findings demonstrate that the role of CAR has extended well beyond its traditional function in xenobiotic metabolism and transport. Endogenous roles involving energy homeostasis, cancer development and prevention, and tissue integrity and regeneration continue to be elucidated. New insights into the mechanisms by which CAR exerts its effects and the precise conditions in which it does so will likely lead to therapeutic advances in many pathologic conditions.

\section{Pregnane X Receptor}

PXR, also known as the steroid and xenobiotic receptor and pregnaneactivated receptor, has been firmly established as the master regulator of the expression of numerous phase I and II DMEs and drug transporters, with CYP3A4 being its most investigated and prototypical target gene in humans (Kliewer et al., 1998; Sueyoshi and Negishi, 2001). Owing to its broad ligand specificity, perturbation of PXR activity can alter the bioavailability, absorption, excretion, and overall disposition of xenobiotics, leading to potentially significant drug-drug, drug-herbal, and drug-environment interactions that impact vital medical treatments (Lehmann et al., 1998; Kliewer and Willson, 2002; di Masi et al., 2009).

Originally cloned in 1998 from a mouse fragment in the EST database (Kliewer et al., 1998), or by screening a human gene library to identify homologs of the Xenopus benzoate X receptor (Blumberg et al., 1998), PXR is classified in the NR1i nuclear receptor family as a liganddependent transcription factor. PXR is predominantly expressed in the liver and intestine, which are routinely exposed to numerous xenobiotics, where it functions as a signaling molecule for the generation of metabolic byproducts of exogenous and endogenous compounds (Kliewer et al., 1998; Lehmann et al., 1998; Jones et al., 2000). Many NRs are known for their three-stranded $\beta$-sheet ligand-binding pocket; however, PXR exhibits a five-stranded $\beta$-sheet ligand-binding pocket that is malleable and largely hydrophilic, permitting the binding of a broad array of structurally diverse chemicals including drugs, endogenous metabolites, and exogenous compounds (Watkins et al., 2001; Ekins and Schuetz, 2002; Ekins et al., 2009). Similar to CAR, inactivated PXR resides in the cytoplasm of hepatocytes of untreated mice, where it translocates to the nucleus when bound to an agonistic ligand, pregnenolone $16 \alpha$-carbonitrile (PCN) (Kawana et al., 2003; Squires et al., 2004). Mechanistically, nuclear translocation of PXR requires an intact nuclear localization signal, which resides within the DNA-binding domain of PXR (Squires et al., 2004). Although ectopically expressed CAR and PXR spontaneously accumulate in the nucleus of immortalized cell lines such as HepG2 cells, without agonist stimulation, nuclear-localized PXR remains inactive, whereas nuclear translocation alone is sufficient to activate CAR (Kawamoto et al., 1999; Kawana et al., 2003). Upon agonist binding, the PXR/RXR heterodimer recruits coactivators such as steroid receptor coactivator 1 and triggers the expression of its target genes (Kliewer et al., 1998). While CAR and PXR both regulate numerous DMEs and transporters, they exhibit different preferential regulation over these genes. This is partly due to the differential binding affinities of CAR and PXR to AG(G/T)TCA repeats in the promoters of these genes (Xie et al., 2000; Faucette et al., 2006). Together, PXR and CAR form a defensive mechanism against 
xenobiotic exposures by coordinately regulating a pleiotropic array of hepatic genes encoding various DMEs and transporters.

In addition to its well-characterized roles in xenobiotic metabolism and detoxification, evidence has shown that PXR also plays important roles in energy metabolism, inflammation, and cell proliferation. Notably, while PXR and CAR exhibit similar roles in xenobiotic disposition by coordinating the inductive expression of DMEs and transporters, PXR appears to differ significantly from CAR in its nonclassic regulatory roles, including energy metabolism and cancer development.

PXR and Energy Homeostasis. Previous studies reveal that activation of PXR by PCN results in decreased blood glucose levels in mice, an effect attributable to PXR-mediated repression of genes such as PEPCK1 and G6Pase that are pivotal to hepatic gluconeogenesis (Bhalla et al., 2004; Kodama et al., 2004). In human hepatocarcinoma Huh7 cells overexpressing transfected human PXR, addition of cAMP induced the expression of G6Pase and PEPCK mRNAs 13- and 20-fold, respectively, while the induction of these genes was markedly repressed by rifampicin, the prototypical activator of human PXR (Kodama et al., 2007). Mechanistically, PXR acts as a corepressor of FOXO1 and FOXA2 and downregulates FOXO1-mediated insulin response sequence activation and transcription of gluconeogenic genes (Kodama et al., 2004). Glutathione $S$-transferase pull-down and coimmunoprecipitation assays demonstrated that PXR directly binds CREB, a cAMPresponse element-binding protein, and represses cAMP-mediated expression of G6Pase thereafter (Kodama et al., 2007). Furthermore, this study showed that the binding affinity between PXR and CREB was strengthened by PCN treatment, which led to decreased binding of CREB to the G6Pase promoter in mice. Additional studies investigating the effect of PXR on bile acid synthesis and gluconeogenesis in HepG2 cells found that human PXR interacts with the coactivator PGC1 $\alpha$ in the presence of rifampicin (Bhalla et al., 2004). This ligand-dependent PGC1-PXR interaction prevents $\mathrm{PGC} 1 \alpha$ from binding to hepatic nuclear factor- $4 \alpha$ and forms functionally inhibitory crosstalk between PXR and hepatic nuclear factor- $4 \alpha$, leading to the repression of PEPCK1.

In contrast with aforementioned findings suggesting a potential glucose-lowering benefit of PXR activation in mice, clinical studies have indicated that treatment with rifampicin increases blood glucose levels in both tuberculosis patients and healthy volunteers (Takasu et al., 1982; Rysä et al., 2013). Such clinical observations correlate with a recent in vitro study using human primary hepatocytes and HepG 2 cells stably expressing human PXR, where activation of PXR by rifampicin and a statin significantly induced the expression of PEPCK1 and G6Pase in both hepatic cell systems (Gotoh and Negishi, 2014, 2015). The serum/glucocorticoid regulated kinase 2 (SGK2) that was also upregulated by human PXR activators appears to be essential for this PXRmediated induction of gluconeogenesis, and the drug-PXR-SGK2 signaling requires the recruitment of the protein phosphatase $2 \mathrm{C} \alpha$ by ligand-activated PXR to dephosphorylate SGK2 at Thr ${ }^{193}$, which in turn facilitates PXR-mediated transactivation of genes encoding gluconeogenesis, including PEPCK and G6Pase. Interestingly, this drug-PXRSGK2 signaling is not present in mice, which may explain some of the discrepancies observed between murine and human studies (Gotoh and Negishi, 2014, 2015). Most recently, Gotoh et al. (2017) further demonstrated that, rather than drug challenges, a low level of glucose induced the phosphorylation of PXR at $\mathrm{Ser}^{350}$ and enhanced gluconeogenesis in cultured HepG2 cells. Immunoprecipitation and in vitro kinase assays revealed that the vaccinia related kinase 1, a serine/threonine kinase, is responsible for the phosphorylation of PXR at $\operatorname{Ser}^{350}$ under low glucose conditions, which enabled the phosphorylated PXR to scaffold protein phosphatase 2C $\alpha$ for subsequent dephosphorylation of SGK2 at $\mathrm{Thr}^{193}$. Knockdown of vaccinia related kinase 1 , on the other hand, markedly repressed the phosphorylation of PXR-Ser ${ }^{350}$, increased SGK2-Thr ${ }^{193}$, and nearly abolished the expression of PEPCK in HepG2 cells cultured under low glucose. Importantly, this low glucosestimulated vaccinia related kinase 1-PXR-PP2C-SGK2 signaling was also observed in mice under fasting conditions, suggesting that this signaling pathway may represent a novel feedback mechanism in response to low glucose that is conserved in both humans and mice. In another study, Oladimeji et al. (2017) observed that high glucose increased the expression and activity of PXR in HepG2 cells and that this induction was partially reversed by the activation of AMP-activated protein kinase, suggesting that PXR activity can be modulated by the energy status of the cells.

Adding yet another layer of complexity to our understanding of the role of PXR in glucose homeostasis, recent studies revealed that PXR also alters the uptake and utilization of glucose. Studies in mice and rats found that activation of PXR with PCN downregulates the expression of glucose transporter 2, the transporter responsible for glucose uptake into hepatocytes during the fed state, and glucokinase, which deactivates G6Pase by phosphorylation (Ling et al., 2016; Hassani-Nezhad-Gashti et al., 2018). Collectively, activation of PXR in various in vivo and in vitro models exhibiting different types of metabolic function has led to mixed outcomes, with PXR activation improving glucose tolerance in some models while worsening glucose homeostasis in others (Hakkola et al., 2016). Multiple confounding factors including genetic variations and experimental conditions may contribute to the observed discrepancies. Clearly, the effects of PXR activation on glucose tolerance in humans require further evaluation.

Unlike the beneficial effects of CAR activation on lipid homeostasis that have been reported by several groups, activation of PXR has been shown to enhance lipogenesis while decreasing lipid oxidation, promoting a fatty liver phenotype (Zhou et al., 2006; Nakamura et al., 2007; Bitter et al., 2015). Using PXR ${ }^{-1-}$ and WT mice, Nakamura et al. (2007) reported that treatment with PCN resulted in downregulation of CPT1A ( $\beta$-oxidation) and mitochondrial 3-hydroxy-3-methylglutarate-CoA synthase 2 (ketogenesis) but upregulation of the stearoyl-CoA desaturase 1 (lipogenesis) in a PXR-dependent manner. At the molecular level, PXR affects the expression of these genes at least partly through crosstalk with the insulin response forkhead factor FoxA2. Unexpectedly, this study also found that untreated $\mathrm{PXR}^{-1-}$ mice developed severe hepatic steatosis accompanied with induction of lipogenesis and repression of fatty acid $\beta$-oxidation reminiscent of those associated with the pharmacological activation of PXR (Nakamura et al., 2007). Whether unidentified endogenous ligands may contribute to this contradictory observation is largely unknown.

Studies using a combination of human PXR transgenic, $\mathrm{PXR}^{-/-}$, and WT mice found that both genetic and pharmacological activation of PXR in the liver resulted in elevated hepatic lipid accumulation, which is associated with induction of the fatty acid translocase protein CD36 without activation of the lipogenic transcriptional factor sterol regulatory element-binding protein-1c (Zhou et al., 2006). On the other hand, genetic PXR ablation protected mice from HFD-induced and genetically induced obesity, hepatic steatosis, and insulin resistance (He et al., 2013). In addition, Ma and coworkers reported that activation of PXR by PCN prevents HFD-induced obesity in AKR/J mice (Ma and Liu, 2012). Potential factors contributing to this discrepancy may include the different genetic backgrounds of mice used, C57BL/6J versus AKR/J, and PCN treatment dosage and schedules. Indeed, PXR-mediated alteration of lipid homeostasis may exhibit tissue, cell type, and species specificities. Activation of PXR in human primary hepatocytes with rifampicin did not induce CD36 expression, and lipid accumulation in the hepatocytes was due to increased fatty acid synthesis and reduced fatty acid $\beta$-oxidation instead of increased free fatty acid uptake as 
observed in the mouse models (Moreau et al., 2009). Another possible mechanism proposed for PXR-dependent increases in hepatic lipid accumulation is the induction of the novel PXR target gene SLC13A5, an uptake transporter that imports citrate from the circulation into the hepatocyte, where it facilitates de novo synthesis of lipids and cholesterol (Li et al., 2015b). Collectively, activation of PXR quite consistently leads to increased hepatic lipid accumulation, while its effects on glucose balance are rather controversy (Fig. 2). The differences in mechanisms between preclinical species and humans require that caution be taken when attempting to define the physiologic relevance of findings in animal models.

PXR in Cancer and Cell Proliferation. PXR-mediated alterations in drug disposition have been known to play a significant role in chemotherapy resistance, since many anticancer agents are substrates of DMEs and efflux transporters that can be upregulated by PXR activation (Zhuo et al., 2014; Oladimeji and Chen, 2018). Although PXR in the liver and intestine accelerates drug clearance in general, tumor-specific expression of PXR becomes an additional barrier to the therapeutic efficacy of anticancer agents (Mani et al., 2005; Chen et al., 2007, 2012). This is exemplified by a recent study investigating the therapeutic efficacy of sorafenib in HCC treatment, where sorafenib was found to enhance its own clearance via CYP3A4 and P-glycoprotein induction in
HCC by the activation of PXR (Feng et al., 2018). Outside of its traditional role of xenobiotic detoxification, accumulating evidence reveals that PXR can also regulate the expression of multiple genes associated with cell apoptosis and proliferation, which play pivotal roles in cancer progression (Masuyama et al., 2007; Gupta et al., 2008; Chen et al., 2009; Pondugula et al., 2016).

Mounting cell-based evidence thus far supports that PXR plays a pleiotropic role in cell proliferation and cancer development in a cell type-specific manner. Treatment of hepatocytes with dexamethasone, a PXR activator, inhibited spontaneous apoptosis by upregulating Bcl-2, an antiapoptotic protein that inhibits p53-mediated apoptosis signaling, and this phenomenon was also confirmed using other PXR agonists in both rat and human hepatocytes (Bailly-Maitre et al., 2001; Zucchini et al., 2005). Additionally, PXR inhibited apoptosis in LS180 colorectal adenocarcinoma cells by inducing Bcl-2 and MCL-1, another antiapoptotic protein, while downregulating proapoptotic proteins such as Bcl-2 antagonist/killer 1 and p53 (Zhou et al., 2008). Further studies probing the mechanistic interactions between PXR and p53 found that WT-p53 can directly bind to PXR, and heterodimerization of PXR and p53 appears to form mutually repressive crosstalk through which each inhibits the other's transcriptional activity in HCT116 and LS180 colon cancer cells. This mutual inhibition protects them against

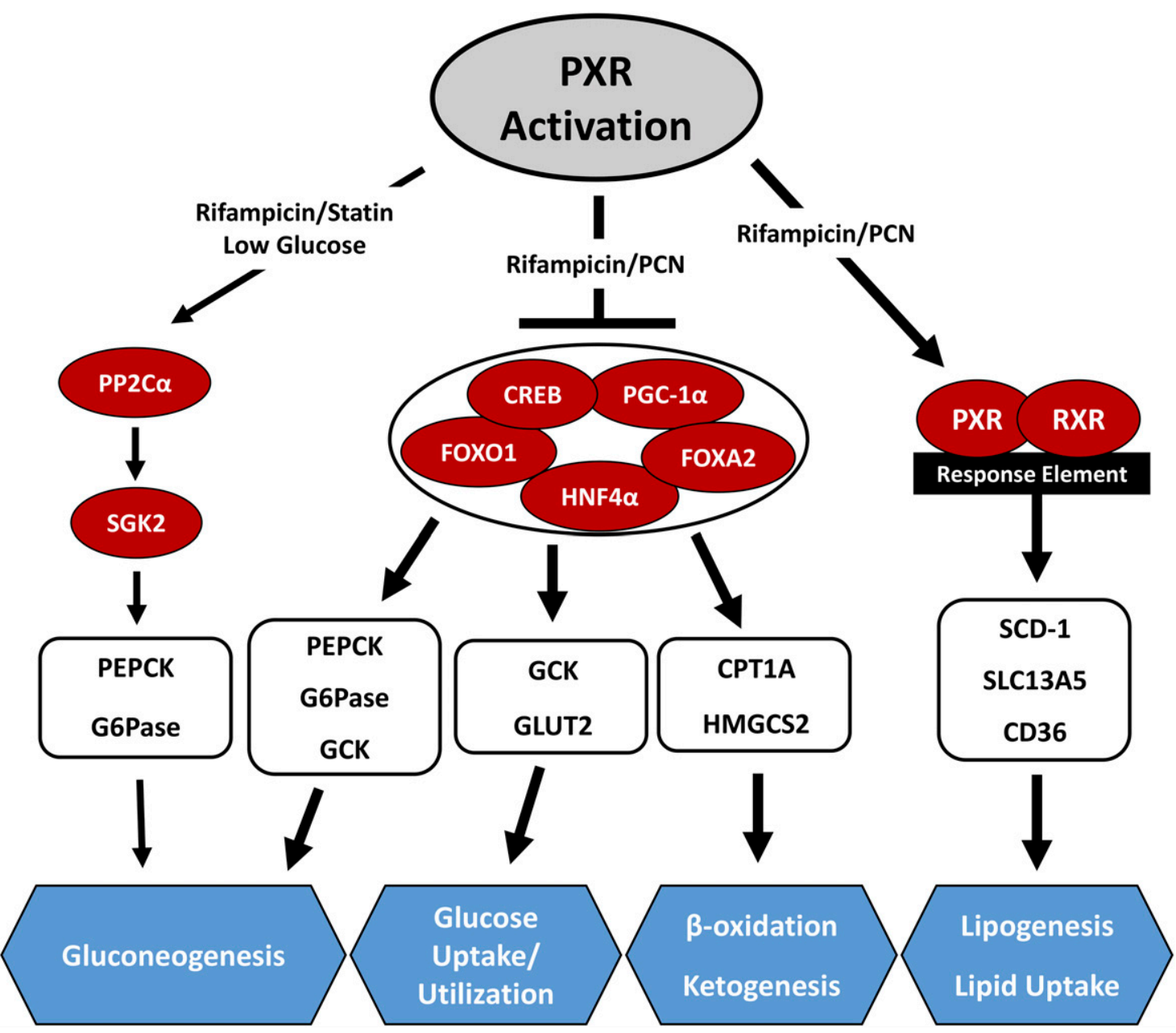

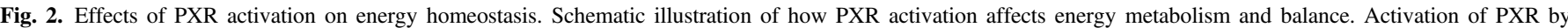

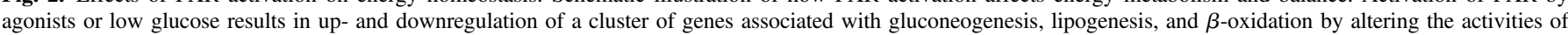

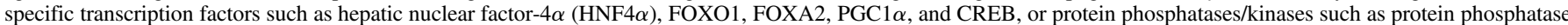
$2 \mathrm{C} \alpha(\mathrm{PP} 2 \mathrm{C} \alpha)$, and SGK2 
chemotherapeutic-induced cell death by decreasing apoptosis and increasing malignant transformation (Elias et al., 2013; Robbins et al., 2016). In addition to its role in liver and colon cancers, PXR is also expressed in prostate cancer, breast cancer, and a number of other tumor tissues, with differential biologic function and tissue and cell type/ context-specific consequences (Miki et al., 2006).

In the case of colorectal cancers, Wang et al. (2011) reported that activation of PXR is sufficient to enhance neoplastic characteristics of LS174T cells and human primary colon tumor cells both in vitro and in xenografted mice in vivo, and pointed out that mechanistically this may involve PXR-dependent induction of fibroblast growth factor 19 expression in cancer. However, using similar approaches, Ouyang et al. (2010) observed PXR-mediated anticancer activity in HT29 cells, another colorectal cancer cell line with relatively low expression of PXR. Stable transfection of PXR in HT29 cells led to repressed cell proliferation, migration, and xenograft growth, which was accompanied by cell-cycle arrest, elevated p21 expression, and inhibition of E2F1 (Ouyang et al., 2010). Interestingly, this report also indicated that expression of PXR is reduced in human colon cancer tissues, albeit using a relatively small sample size (Ouyang et al., 2010). A tumor-suppressive role of PXR was further supported by another report where intestine-specific activation of PXR by rifaximin significantly reduced azoxymethane/dextran sulfate sodium-induced colon cancer in human PXR transgenic but not WT or $\mathrm{PXR}^{-1-}$ mice, possibly through the PXR-NF- $\kappa \mathrm{B}$ axis (Cheng et al., 2014).

In addition to cancer development, PXR has been shown to be important in liver regeneration by augmenting the proliferation of hepatocytes (Dai et al., 2008; Elcombe et al., 2012). In fact, PXR was necessary for full liver regeneration in mice after a partial hepatectomy, with the $\mathrm{PXR}^{-1-}$ mice exhibiting severe inhibition of hepatocyte proliferation 3 days after hepatectomy surgery (Dai et al., 2008). $\mathrm{PXR}^{-1-}$ mice showed inactivation of STAT3 at 5 days postsurgery, which was the most likely cause of hepatocyte quiescence (Dai et al., 2008). While activation of PXR in WT mice did not enhance hepatocyte proliferation, cotreatment of PCN with activators of either CAR or peroxisome proliferator-activated receptor $\alpha$ led to synergistic enhancement of hepatocyte proliferation (Shizu et al., 2013). Collectively, activation of PXR perturbs the balance of cell proliferation and apoptosis in cell-, tissue-, and species-specific manners without an overarching phenotype, making the study of PXR complex in different cancer types.

Additional Nontraditional Functions of PXR. Studies have shown that PXR is also expressed in immune cells, such as $\mathrm{T}$ and B lymphocytes, and in the skin of mice and humans, where perturbation of PXR expression and activity alters the immune response (Dubrac et al., 2010; Haslam et al., 2013; Elentner et al., 2015). Many patients with atopic dermatitis have compromised immune barrier function, which leads to an increase in the penetration of lipophilic pollutants (Oetjen et al., 2018). This penetration has been shown to trigger PXR activation in keratinocytes and a subsequent hyper-responsive immune response, further impairing the barrier function (Oetjen et al., 2018). Specifically, Elenter et al. (2018) reported that transgenic mice expressing constitutively activated human PXR display increased transepidermal water loss, abnormal stratum corneum lipids, focal epidermal hyperplasia, and increased expression of local $\mathrm{T}$ cells.

The same compromise in barrier function exhibited in atopic dermatitis is also observed in the gastrointestinal tract in diseases such as inflammatory bowel disease and Crohn's disease, and PXR plays a role in both of these diseases by increasing epithelial permeability (Terc et al., 2014). Additionally, PXR has been shown to regulate the intestinal epithelial wound healing response, allowing mutations to reduce the healing response and leading to an increase in inflammatory bowel disease risk factors. This has been shown by using PXR agonists as protective agents that prevent intestinal inflammation from occurring (Terc et al., 2014). It is suggested that PXR plays a role in the healing response by modulating gene transcription, thereby upregulating genes that are related to metabolic functioning, while hindering inflammatory genes (Mencarelli et al., 2010). Beyond the role of PXR in the disease state of the gastrointestinal tract, PXR activation plays a major role in the maintenance of homeostasis of bile acids, which can affect the potential progression of many cholesterol-related diseases.

As described throughout this review, many xenobiotics and endobiotics activate PXR, leading to the regulation of key enzymes that have been implicated in a wide array of physiologic activities. There is an abundance of knowledge on the role of PXR in xenobiotic metabolism, and recently the evidence has shifted to the more critical nontraditional role that PXR plays in the regulation of endogenous functions, which has led to interest in uncovering the magnitude of PXR's influence. However, more information is needed to determine whether PXR may eventually be used as a target to prevent and treat diseases.

\section{Conclusions}

Over the past 20 years or so, significant advances have been achieved in our understanding of the roles of XRs in the transcriptional regulation of genes involved in xenobiotic absorption, distribution, metabolism, excretion, and toxicology. Accumulating evidence shows that these traditional xenobiotic sensors also play pivotal roles in modulating energy homeostasis, cell proliferation, cell migration, apoptosis, inflammation, and immune response, which may eventually alter the clinical consequences of metabolic disorders, obesity, and diabetes, as well as various cancers. It is evident now that although XRs such as CAR and PXR continue to be appreciated as master regulators that control xenobiotic disposition and detoxification, newly heightened research studies are focusing on 1) the identification of previously unknown physiologic/pathophysiologic functions of XRs, 2) understanding the molecular mechanisms underlying the noncanonical roles of XRs, and 3) exploring XRs as potentially novel therapeutic targets for disease conditions such as metabolic disorders and cancers. We have witnessed rapid progression in our understanding of the endobiotic roles of CAR and PXR and in our ability to decipher the mechanisms of their activation. Unlike typical ligand-dependent NRs, CAR activity can be altered by numerous cellular signaling pathways, which themselves are often associated with important physiologic and pathophysiologic conditions. Notably, in animal models, while activation of both CAR and PXR benefits diabetic conditions by repressing hepatic gluconeogenesis, the two XRs display contrasting effects on lipogenesis and fatty acid $\beta$-oxidation. Given that many drugs are dual activators of both CAR and PXR, the potential clinical application of these findings is rather complicated and requires further elucidation.

One key point discussed in this article is that both CAR and PXR present significant cell-type, tissue, and species specificities with regard to their noncanonical functions. For instance, while activation of PXR enhanced the neoplastic characteristics of LS174T cells, it repressed the proliferation of HT29 cells both in vitro and in xenografted mice in vivo. Pharmacologic activation of PXR resulted in conflicting effects on HFDinduced fatty liver in mice with $\mathrm{C} 57 \mathrm{BL} / 6 \mathrm{~J}$ versus $\mathrm{AKR} / \mathrm{J}$ genetic background. To date, the majority of these new findings have come from experiments conducted in rodent animal models, and direct extrapolation of these data to humans can be misleading and risky. It is rather convincing now that activation of CAR and PXR in mice enhances cell proliferation and tumor progression, and many of their agonists are wellknown tumor promoters in rodents. Nevertheless, the role of these XRs in human cancer development is inconclusive in general and sometimes contradictory to the findings in rodent animals. In the case of CAR, both 
PB and TCPOBOP exhibit potent tumor-promoting effects in mice in a CAR-dependent manner. However, clinical use of PB over an extended period of time has never been associated with an increased incidence of cancer in humans. It is worth noting that, in addition to the known species differences, a lack of in-depth investigation into human XR function in appropriate models adds to the uncertainty and contradictory outcomes obtained thus far. It is anticipated that the use of novel threedimensional physiologically relevant human preclinical models, such as hepatocyte spheroid cultures, organ-on-chip platforms, and threedimensional bioprinted human tissues, will provide alternative approaches to overcome these challenges. Collectively, exciting new discoveries of XR-mediated endobiotic effects have been made through flourishing new studies. Extrapolation of findings from animal studies is hindered by the rather paradoxical effects observed between human and rodent CAR and PXR on energy homeostasis and cell proliferation. To fully appreciate the clinical impact of these XRs in diseases such as metabolic disorders and cancers, more intensive human studies are warranted in the future.

\section{Acknowledgments}

We are grateful to members of the Wang laboratory for discussions and comments on the paper. We apologize to the scientists who made contributions to the field but have not been cited due to space limitations.

\section{Authorship Contributions}

Participated in research design: Mackowiak, Hodge, Stern, Wang.

Wrote or contributed to the writing of the manuscript: Mackowiak, Hodge, Stern, Wang.

\section{References}

Baes M, Gulick T, Choi HS, Martinoli MG, Simha D, and Moore DD (1994) A new orphan member of the nuclear hormone receptor superfamily that interacts with a subset of retinoic acid response elements. Mol Cell Biol 14:1544-1552.

Bailly-Maitre B, de Sousa G, Boulukos K, Gugenheim J, and Rahmani R (2001) Dexamethasone inhibits spontaneous apoptosis in primary cultures of human and rat hepatocytes via Bcl-2 and Bcl-xL induction. Cell Death Differ 8:279-288.

Banerjee M, Robbins D, and Chen T (2015) Targeting xenobiotic receptors PXR and CAR in human diseases. Drug Discov Today 20:618-628.

Bhalla S, Ozalp C, Fang S, Xiang L, and Kemper JK (2004) Ligand-activated pregnane X receptor interferes with HNF-4 signaling by targeting a common coactivator PGC- $1 \alpha$. Functional implications in hepatic cholesterol and glucose metabolism. J Biol Chem 279:45139-45147.

Bitter A, Rümmele P, Klein K, Kandel BA, Rieger JK, Nüssler AK, Zanger UM, Trauner M, Schwab M, and Burk O (2015) Pregnane X receptor activation and silencing promote steatosis of human hepatic cells by distinct lipogenic mechanisms. Arch Toxicol 89:2089-2103.

Blanco-Bose WE, Murphy MJ, Ehninger A, Offner S, Dubey C, Huang W, Moore DD, and Trumpp A (2008) C-Myc and its target FoxM1 are critical downstream effectors of constitutive androstane receptor (CAR) mediated direct liver hyperplasia. Hepatology 48 1302-1311.

Blumberg B, Kang H, Bolado J, Jr, Chen H, Craig AG, Moreno TA, Umesono K, Perlmann T, De Robertis EM, and Evans RM (1998) BXR, an embryonic orphan nuclear receptor activated by a novel class of endogenous benzoate metabolites. Genes Dev 12:1269-1277.

Boussadia B, Gangarossa G, Mselli-Lakhal L, Rousset MC, de Bock F, Lassere F, Ghosh C Pascussi JM, Janigro D, and Marchi N (2016) Lack of CAR impacts neuronal function and cerebrovascular integrity in vivo. Exp Neurol 283:39-48.

Braeuning A (2014) Liver cell proliferation and tumor promotion by phenobarbital: relevance for humans? Arch Toxicol 88:1771-1772.

Braeuning A, Gavrilov A, Geissler M, Wenz C, Colnot S, Templin MF, Metzger U, Römer M, Zell A, and Schwarz M (2016) Tumor promotion and inhibition by phenobarbital in livers of conditional Apc-deficient mice. Arch Toxicol 90:1481-1494.

Chakraborty S, Kanakasabai S, and Bright JJ (2011) Constitutive androstane receptor agonis CITCO inhibits growth and expansion of brain tumour stem cells. Br J Cancer 104:448-459.

Chen Y, Tang Y, Chen S, and Nie D (2009) Regulation of drug resistance by human pregnane X receptor in breast cancer. Cancer Biol Ther 8:1265-1272.

Chen Y, Tang Y, Guo C, Wang J, Boral D, and Nie D (2012) Nuclear receptors in the multidrug resistance through the regulation of drug-metabolizing enzymes and drug transporters. Biochem Pharmacol 83:1112-1126.

Chen Y, Tang Y, Wang MT, Zeng S, and Nie D (2007) Human pregnane X receptor and resistance to chemotherapy in prostate cancer. Cancer Res 67:10361-10367.

Cheng J, Fang ZZ, Nagaoka K, Okamoto M, Qu A, Tanaka N, Kimura S, and Gonzalez FJ (2014) Activation of intestinal human pregnane $\mathrm{X}$ receptor protects against azoxymethane/dextran sulfate sodium-induced colon cancer. J Pharmacol Exp Ther 351:559-567.

Cheng S, Zou M, Liu Q, Kuang J, Shen J, Pu S, Chen L, Li H, Wu T, Li R, et al. (2017) Activation of constitutive androstane receptor prevents cholesterol gallstone formation. Am J Pathol 187: 808-818.

Choi HS, Chung M, Tzameli I, Simha D, Lee YK, Seol W, and Moore DD (1997) Differential transactivation by two isoforms of the orphan nuclear hormone receptor CAR. J Biol Chem 272 23565-23571.
Choi YJ, Zhou D, Barbosa ACS, Niu Y, Guan X, Xu M, Ren S, Nolin TD, Liu Y, and Xie W (2018) Activation of constitutive androstane receptor ameliorates renal ischemia-reperfusioninduced kidney and liver injury. Mol Pharmacol 93:239-250.

Clavien PA, Lesurtel M, Bossuyt PM, Gores GJ, Langer B, and Perrier A; OLT for HCC Consensus Group (2012) Recommendations for liver transplantation for hepatocellular carcinoma: an international consensus conference report. Lancet Oncol 13:e11-e22.

Coulouarn C, Factor VM, Andersen JB, Durkin ME, and Thorgeirsson SS (2009) Loss of miR-122 expression in liver cancer correlates with suppression of the hepatic phenotype and gain of metastatic properties. Oncogene 28:3526-3536.

Dai G, He L, Bu P, and Wan YJ (2008) Pregnane X receptor is essential for normal progression of liver regeneration. Hepatology 47:1277-1287.

Dash AK, Yende AS, Jaiswal B, and Tyagi RK (2017) Heterodimerization of retinoid X receptor with xenobiotic receptor partners occurs in the cytoplasmic compartment: mechanistic insights of events in living cells. Exp Cell Res 360:337-346.

De Mattia E, Cecchin E, Roncato R, and Toffoli G (2016) Pregnane X receptor, constitutive androstane receptor and hepatocyte nuclear factors as emerging players in cancer precision medicine. Pharmacogenomics 17:1547-1571.

Denison MS and Nagy SR (2003) Activation of the aryl hydrocarbon receptor by structurally diverse exogenous and endogenous chemicals. Annu Rev Pharmacol Toxicol 43:309-334.

de Vries EM, Oosterman JE, Eggink HM, de Goede P, Sen S, Foppen E, Boudzovitch-Surovtseva O, Boelen A, Romijn JA, laFleur SE, et al. (2017) Effects of meal composition and meal timing on the expression of genes involved in hepatic drug metabolism in rats. PLoS One 12:e185520. di Masi A, De Marinis E, Ascenzi P, and Marino M (2009) Nuclear receptors CAR and PXR: molecular, functional, and biomedical aspects. Mol Aspects Med 30:297-343.

Dong B, Lee JS, Park YY, Yang F, Xu G, Huang W, Finegold MJ, and Moore DD (2015) Activating CAR and $\beta$-catenin induces uncontrolled liver growth and tumorigenesis. Nat Commun 6:5944.

Dong B, Saha PK, Huang W, Chen W, Abu-Elheiga LA, Wakil SJ, Stevens RD, Ilkayeva O, Newgard CB, Chan L, et al. (2009) Activation of nuclear receptor CAR ameliorates diabetes and fatty liver disease. Proc Natl Acad Sci USA 106:18831-18836.

Dreyer C, Krey G, Keller H, Givel F, Helftenbein G, and Wahli W (1992) Control of the peroxisomal $\beta$-oxidation pathway by a novel family of nuclear hormone receptors. Cell 68:879-887. Dubrac S, Elentner A, Ebner S, Horejs-Hoeck J, and Schmuth M (2010) Modulation of T lymphocyte function by the pregnane X receptor. J Immunol 184:2949-2957.

Ekins S, Kortagere S, Iyer M, Reschly EJ, Lill MA, Redinbo MR, and Krasowski MD (2009) Challenges predicting ligand-receptor interactions of promiscuous proteins: the nuclear receptor PXR. PLOS Comput Biol 5:e1000594.

Ekins S and Schuetz E (2002) The PXR crystal structure: the end of the beginning. Trends Pharmacol Sci 23:49-50.

Elcombe CR, Elcombe BM, Foster JR, Chang SC, Ehresman DJ, and Butenhoff JL (2012) Hepatocellular hypertrophy and cell proliferation in Sprague-Dawley rats from dietary exposure to potassium perfluorooctanesulfonate results from increased expression of xenosensor nuclear receptors PPAR $\alpha$ and CAR/PXR. Toxicology 293:16-29.

Elcombe CR, Peffer RC, Wolf DC, Bailey J, Bars R, Bell D, Cattley RC, Ferguson SS, Geter D, Goetz A, et al. (2014) Mode of action and human relevance analysis for nuclear receptormediated liver toxicity: a case study with phenobarbital as a model constitutive androstane receptor (CAR) activator. Crit Rev Toxicol 44:64-82.

Elentner A, Ortner D, Clausen B, Gonzalez FJ, Fernández-Salguero PM, Schmuth M, and Dubrac S (2015) Skin response to a carcinogen involves the xenobiotic receptor pregnane $\mathrm{X}$ receptor. Exp Dermatol 24:835-840.

Elentner A, Schmuth M, Yannoutsos N, Eichmann TO, Gruber R, Radner FPW, Hermann M, Del Frari B, and Dubrac S (2018) Epidermal overexpression of xenobiotic receptor PXR impairs the epidermal barrier and triggers Th2 immune response. J Invest Dermatol 138:109-120.

Elias A, Wu J, and Chen T (2013) Tumor suppressor protein p53 negatively regulates human pregnane X receptor activity. Mol Pharmacol 83:1229-1236.

Faucette SR, Sueyoshi T, Smith CM, Negishi M, Lecluyse EL, and Wang H (2006) Differential regulation of hepatic $C Y P 2 B 6$ and $C Y P 3 A 4$ genes by constitutive androstane receptor but not pregnane X receptor. J Pharmacol Exp Ther 317:1200-1209.

Feng F, Jiang Q, Cao S, Cao Y, Li R, Shen L, Zhu H, Wang T, Sun L, Liang E, et al. (2018) Pregnane X receptor mediates sorafenib resistance in advanced hepatocellular carcinoma. Biochim Biophys Acta 1862:1017-1030.

Forman BM and Evans RM (1995) Nuclear hormone receptors activate direct, inverted, and everted repeats. Ann N Y Acad Sci 761:29-37.

Forman BM, Tzameli I, Choi HS, Chen J, Simha D, Seol W, Evans RM, and Moore DD (1998) Androstane metabolites bind to and deactivate the nuclear receptor CAR- $\beta$. Nature 395 612-615.

Gachon F, Olela FF, Schaad O, Descombes P, and Schibler U (2006) The circadian PAR-domain basic leucine zipper transcription factors DBP, TEF, and HLF modulate basal and inducible xenobiotic detoxification. Cell Metab 4:25-36.

Gao J, He J, Zhai Y, Wada T, and Xie W (2009) The constitutive androstane receptor is an antiobesity nuclear receptor that improves insulin sensitivity. J Biol Chem 284:25984-25992.

Gao J and Xie W (2012) Targeting xenobiotic receptors PXR and CAR for metabolic diseases. Trends Pharmacol Sci 33:552-558.

Gao J, Yan J, Xu M, Ren S, and Xie W (2015) CAR suppresses hepatic gluconeogenesis by facilitating the ubiquitination and degradation of PGC1 $\alpha$. Mol Endocrinol 29:1558-1570.

Gotoh S, Miyauchi Y, Moore R, and Negishi M (2017) Glucose elicits serine/threonine kinase VRK1 to phosphorylate nuclear pregnane $\mathrm{X}$ receptor as a novel hepatic gluconeogenic signal. Cell Signal 40:200-209.

Gotoh S and Negishi M (2014) Serum- and glucocorticoid-regulated kinase 2 determines drugactivated pregnane $\mathrm{X}$ receptor to induce gluconeogenesis in human liver cells. J Pharmacol Exp Ther 348:131-140.

Gotoh S and Negishi M (2015) Statin-activated nuclear receptor PXR promotes SGK2 dephosphorylation by scaffolding PP2C to induce hepatic gluconeogenesis. Sci Rep 5:14076.

Gupta D, Venkatesh M, Wang H, Kim S, Sinz M, Goldberg GL, Whitney K, Longley C, and Man $\mathrm{S}$ (2008) Expanding the roles for pregnane $\mathrm{X}$ receptor in cancer: proliferation and drug resistance in ovarian cancer. Clin Cancer Res 14:5332-5340.

Gutiérrez-Vázquez C and Quintana FJ (2018) Regulation of the immune response by the aryl hydrocarbon receptor. Immunity 48:19-33.

Haines C, Elcombe BM, Chatham LR, Vardy A, Higgins LG, Elcombe CR, and Lake BG (2018) Comparison of the effects of sodium phenobarbital in wild type and humanized constitutive 
androstane receptor (CAR)/pregnane $\mathrm{X}$ receptor (PXR) mice and in cultured mouse, rat and human hepatocytes. Toxicology 396-397:23-32.

Hakkola J, Rysä J, and Hukkanen J (2016) Regulation of hepatic energy metabolism by the nuclear receptor PXR. Biochim Biophys Acta 1859:1072-1082.

Handschin C and Meyer UA (2003) Induction of drug metabolism: the role of nuclear receptors. Pharmacol Rev 55:649-673.

Hao R, Su S, Wan Y, Shen F, Niu B, Coslo DM, Albert I, Han X, and Omiecinski CJ (2016) Bioinformatic analysis of microRNA networks following the activation of the constitutive androstane receptor (CAR) in mouse liver. Biochim Biophys Acta 1859:1228-1237.

Haslam IS, Pitre A, Schuetz JD, and Paus R (2013) Protection against chemotherapy-induced alopecia: targeting ATP-binding cassette transporters in the hair follicle? Trends Pharmacol Sci 34.599-604.

Hassani-Nezhad-Gashti F, Rysä J, Kummu O, Näpänkangas J, Buler M, Karpale M, Hukkanen J, and Hakkola J (2018) Activation of nuclear receptor PXR impairs glucose tolerance and dysregulates GLUT2 expression and subcellular localization in liver. Biochem Pharmacol 148 253-264.

He J, Gao J, Xu M, Ren S, Stefanovic-Racic M, O’Doherty RM, and Xie W (2013) PXR ablation alleviates diet-induced and genetic obesity and insulin resistance in mice. Diabetes 62 $1876-1887$.

Herzig S, Long F, Jhala US, Hedrick S, Quinn R, Bauer A, Rudolph D, Schutz G, Yoon C, Puigserver P, et al. (2001) CREB regulates hepatic gluconeogenesis through the coactivator PGC-1. Nature 413:179-183.

Hollenberg SM, Weinberger C, Ong ES, Cerelli G, Oro A, Lebo R, Thompson EB, Rosenfeld MG, and Evans RM (1985) Primary structure and expression of a functional human glucocorticoid receptor cDNA. Nature 318:635-641.

Honkakoski P and Negishi M (1997) Characterization of a phenobarbital-responsive enhancer module in mouse P450 Cyp2b10 gene. J Biol Chem 272:14943-14949.

Honkakoski P, Sueyoshi T, and Negishi M (2003) Drug-activated nuclear receptors CAR and PXR. Ann Med 35:172-182.

Honkakoski P, Zelko I, Sueyoshi T, and Negishi M (1998) The nuclear orphan receptor CARretinoid $\mathrm{X}$ receptor heterodimer activates the phenobarbital-responsive enhancer module of the CYP2B gene. Mol Cell Biol 18:5652-5658.

Huang W, Zhang J, Chua SS, Qatanani M, Han Y, Granata R, and Moore DD (2003) Induction of bilirubin clearance by the constitutive androstane receptor (CAR). Proc Natl Acad Sci USA 100: $4156-4161$

Huang W, Zhang J, Washington M, Liu J, Parant JM, Lozano G, and Moore DD (2005) Xenobiotic stress induces hepatomegaly and liver tumors via the nuclear receptor constitutive androstane receptor. Mol Endocrinol 19:1646-1653.

Hudson GM, Flannigan KL, Erickson SL, Vicentini FA, Zamponi A, Hirota CL, Alston L, Altier C, Ghosh S, Rioux KP, et al. (2017) Constitutive androstane receptor regulates the intestinal mucosal response to injury. Br J Pharmacol 174:1857-1871.

Ikuta T, Eguchi H, Tachibana T, Yoneda Y, and Kawajiri K (1998) Nuclear localization and export signals of the human aryl hydrocarbon receptor. J Biol Chem 273:2895-2904.

Issemann I and Green S (1990) Activation of a member of the steroid hormone receptor superfamily by peroxisome proliferators. Nature 347:645-650.

Jensen EV and Jacobson HI (1960) Fate of steroid estrogens in target tissues, in Biological Activities of Steroids in Relation to Cancer, pp 161-178, Elsevier, Academic Press, New York.

Jones SA, Moore LB, Shenk JL, Wisely GB, Hamilton GA, McKee DD, Tomkinson NC, LeCluyse EL, Lambert MH, Willson TM, et al. (2000) The pregnane X receptor: a promiscuous xenobiotic receptor that has diverged during evolution. Mol Endocrinol 14:27-39.

Kamino H, Moore R, and Negishi M (2011a) Role of a novel CAR-induced gene, TUBA8, in hepatocellular carcinoma cell lines. Cancer Genet 204:382-391.

Kamino H, Yamazaki Y, Saito K, Takizawa D, Kakizaki S, Moore R, and Negishi M (2011b) Nuclear receptor CAR-regulated expression of the FAM84A gene during the development of mouse liver tumors. Int J Oncol 38:1511-1520.

Kanno Y, Suzuki M, Nakahama T, and Inouye Y (2005) Characterization of nuclear localization signals and cytoplasmic retention region in the nuclear receptor CAR. Biochim Biophys Acto 1745:215-222.

Kawamoto T, Sueyoshi T, Zelko I, Moore R, Washburn K, and Negishi M (1999) Phenobarbitalresponsive nuclear translocation of the receptor CAR in induction of the $C Y P 2 B$ gene. Mol Cell Biol 19:6318-6322.

Kawana K, Ikuta T, Kobayashi Y, Gotoh O, Takeda K, and Kawajiri K (2003) Molecular mechanism of nuclear translocation of an orphan nuclear receptor, SXR. Mol Pharmacol 63 524-531.

Kazantseva YA, Pustylnyak YA, and Pustylnyak VO (2016) Role of nuclear constitutive androstane receptor in regulation of hepatocyte proliferation and hepatocarcinogenesis. Biochemistry (Mosc) 81:338-347.

Kazantseva YA, Yarushkin AA, Mostovich LA, Pustylnyak YA, and Pustylnyak VO (2015) Xenosensor CAR mediates down-regulation of miR-122 and up-regulation of miR-122 targets in the liver. Toxicol Appl Pharmacol 288:26-32.

Kettner NM, Voicu H, Finegold MJ, Coarfa C, Sreekumar A, Putluri N, Katchy CA, Lee C, Moore $\mathrm{DD}$, and Fu L (2016) Circadian homeostasis of liver metabolism suppresses hepatocarcinogenesis. Cancer Cell 30:909-924.

Kliewer SA, Moore JT, Wade L, Staudinger JL, Watson MA, Jones SA, McKee DD, Oliver BB, Willson TM, Zetterström RH, et al. (1998) An orphan nuclear receptor activated by pregnanes defines a novel steroid signaling pathway. Cell 92:73-82

Kliewer SA and Willson TM (2002) Regulation of xenobiotic and bile acid metabolism by the nuclear pregnane X receptor. J Lipid Res 43:359-364.

Kodama S, Koike C, Negishi M, and Yamamoto Y (2004) Nuclear receptors CAR and PXR cross talk with FOXO1 to regulate genes that encode drug-metabolizing and gluconeogenic enzymes. Mol Cell Biol 24:7931-7940.

Kodama S, Moore R, Yamamoto Y, and Negishi M (2007) Human nuclear pregnane X receptor cross-talk with CREB to repress cAMP activation of the glucose-6-phosphatase gene. Biochem J 407:373-381.

Köhle C and Bock KW (2009) Coordinate regulation of human drug-metabolizing enzymes, and conjugate transporters by the Ah receptor, pregnane $\mathrm{X}$ receptor and constitutive androstane receptor. Biochem Pharmacol 77:689-699.

Koike C, Moore R, and Negishi M (2007) Extracellular signal-regulated kinase is an endogenous signal retaining the nuclear constitutive active/androstane receptor (CAR) in the cytoplasm of mouse primary hepatocytes. Mol Pharmacol 71:1217-1221.
Kumar GN and Surapaneni S (2001) Role of drug metabolism in drug discovery and development. Med Res Rev 21:397-411.

Lahtela JT, Arranto AJ, and Sotaniemi EA (1985) Enzyme inducers improve insulin sensitivity in non-insulin-dependent diabetic subjects. Diabetes 34:911-916.

La Vecchia C and Negri E (2014) A review of epidemiological data on epilepsy, phenobarbital, and risk of liver cancer. Eur J Cancer Prev 23:1-7.

Lehmann JM, McKee DD, Watson MA, Willson TM, Moore JT, and Kliewer SA (1998) The human orphan nuclear receptor PXR is activated by compounds that regulate CYP3A4 gene expression and cause drug interactions. J Clin Invest 102:1016-1023.

Li D, Mackowiak B, Brayman TG, Mitchell M, Zhang L, Huang SM, and Wang H (2015a) Genome-wide analysis of human constitutive androstane receptor (CAR) transcriptome in wildtype and CAR-knockout HepaRG cells. Biochem Pharmacol 98:190-202.

Li H, Chen T, Cottrell J, and Wang H (2009) Nuclear translocation of adenoviral-enhanced yellow fluorescent protein-tagged-human constitutive androstane receptor (hCAR): a novel tool for screening hCAR activators in human primary hepatocytes. Drug Metab Dispos 37:1098-1106.

$\mathrm{Li} \mathrm{H}$ and Wang H (2010) Activation of xenobiotic receptors: driving into the nucleus. Expert Opin Drug Metab Toxicol 6:409-426.

Li L, Li H, Garzel B, Yang H, Sueyoshi T, Li Q, Shu Y, Zhang J, Hu B, Heyward S, et al. (2015b) SLC13A5 is a novel transcriptional target of the pregnane $\mathrm{X}$ receptor and sensitizes drug-induced steatosis in human liver. Mol Pharmacol 87:674-682.

Ling Z, Shu N, Xu P, Wang F, Zhong Z, Sun B, Li F, Zhang M, Zhao K, Tang X, et al. (2016) Involvement of pregnane $\mathrm{X}$ receptor in the impaired glucose utilization induced by atorvastatin in hepatocytes. Biochem Pharmacol 100:98-111.

Lubahn DB, Joseph DR, Sullivan PM, Willard HF, French FS, and Wilson EM (1988) Cloning of human androgen receptor complementary DNA and localization to the X chromosome. Science 240:327-330.

Lynch C, Pan Y, Li L, Heyward S, Moeller T, Swaan PW, and Wang H (2014) Activation of the constitutive androstane receptor inhibits gluconeogenesis without affecting lipogenesis or fatty acid synthesis in human hepatocytes. Toxicol Appl Pharmacol 279:33-42.

Ma Y and Liu D (2012) Activation of pregnane X receptor by pregnenolone $16 \alpha$-carbonitrile prevents high-fat diet-induced obesity in AKR/J mice. PLoS One 7:e38734.

Maeda J, Inoue K, Ichimura R, Takahashi M, Kodama Y, Saito N, and Yoshida M (2015) Essentia role of constitutive androstane receptor in Ginkgo biloba extract induced liver hypertrophy and hepatocarcinogenesis. Food Chem Toxicol 83:201-209.

Maglich JM, Lobe DC, and Moore JT (2009) The nuclear receptor CAR (NR1I3) regulates serum triglyceride levels under conditions of metabolic stress. J Lipid Res 50:439-445.

Maglich JM, Watson J, McMillen PJ, Goodwin B, Willson TM, and Moore JT (2004) The nuclear receptor CAR is a regulator of thyroid hormone metabolism during caloric restriction. $J$ Biol Chem 279:19832-19838.

Mani S, Huang H, Sundarababu S, Liu W, Kalpana G, Smith AB, and Horwitz SB (2005) Activation of the steroid and xenobiotic receptor (human pregnane $\mathrm{X}$ receptor) by nontaxane microtubule-stabilizing agents. Clin Cancer Res 11:6359-6369.

Marmugi A, Lukowicz C, Lasserre F, Montagner A, Polizzi A, Ducheix S, Goron A, GametPayrastre L, Gerbal-Chaloin S, Pascussi JM, et al. (2016) Activation of the constitutive androstane receptor induces hepatic lipogenesis and regulates Pnpla3 gene expression in a LXRindependent way. Toxicol Appl Pharmacol 303:90-100.

Martini T, Stojan J, Rozman D, and Prosenc Zmrzljak U (2017) Interaction of PER2 with the constitutive androstane receptor possibly links circadian rhythms to metabolism. Acta Chim Slov 64:571-576

Masuyama H, Nakatsukasa H, Takamoto N, and Hiramatsu Y (2007) Down-regulation of pregnane $\mathrm{X}$ receptor contributes to cell growth inhibition and apoptosis by anticancer agents in endometrial cancer cells. Mol Pharmacol 72:1045-1053.

Mencarelli A, Migliorati M, Barbanti M, Cipriani S, Palladino G, Distrutti E, Renga B, and Fiorucci S (2010) Pregnane-X-receptor mediates the anti-inflammatory activities of rifaximin on detoxification pathways in intestinal epithelial cells. Biochem Pharmaco 80:1700-1707.

Miao J, Fang S, Bae Y, and Kemper JK (2006) Functional inhibitory cross-talk between constitutive androstane receptor and hepatic nuclear factor-4 in hepatic lipid/glucose metabolism is mediated by competition for binding to the DR1 motif and to the common coactivators, GRIP-1 and PGC-1 $\alpha$. J Biol Chem 281:14537-14546.

Miki Y, Suzuki T, Kitada K, Yabuki N, Shibuya R, Moriya T, Ishida T, Ohuchi N, Blumberg B, and Sasano H (2006) Expression of the steroid and xenobiotic receptor and its possible target gene, organic anion transporting polypeptide-A, in human breast carcinoma. Cancer Res 66 535-542.

Misrahi M, Atger M, d'Auriol L, Loosfelt H, Meriel C, Fridlansky F, Guiochon-Mantel A, Galibert F, and Milgrom E (1987) Complete amino acid sequence of the human progesterone receptor deduced from cloned cDNA. Biochem Biophys Res Commun 143:740-748.

Mo L, Shen J, Liu Q, Zhang Y, Kuang J, Pu S, Cheng S, Zou M, Jiang W, Jiang C, et al. (2016) Irisin is regulated by CAR in liver and is a mediator of hepatic glucose and lipid metabolism. Mol Endocrinol 30:533-542.

Moore LB, Parks DJ, Jones SA, Bledsoe RK, Consler TG, Stimmel JB, Goodwin B, Liddle C, Blanchard SG, Willson TM, et al. (2000) Orphan nuclear receptors constitutive androstane receptor and pregnane $\mathrm{X}$ receptor share xenobiotic and steroid ligands. J Biol Chem 275: $15122-15127$

Moreau A, Téruel C, Beylot M, Albalea V, Tamasi V, Umbdenstock T, Parmentier Y, Sa-Cunha A, Suc B, Fabre JM, et al. (2009) A novel pregnane X receptor and S14-mediated lipogenic pathway in human hepatocyte. Hepatology 49:2068-2079.

Mutoh S, Osabe M, Inoue K, Moore R, Pedersen L, Perera L, Rebolloso Y, Sueyoshi T, and Negishi M (2009) Dephosphorylation of threonine 38 is required for nuclear translocation and activation of human xenobiotic receptor CAR (NR1I3). J Biol Chem 284:34785-34792.

Mutoh S, Sobhany M, Moore R, Perera L, Pedersen L, Sueyoshi T, and Negishi M (2013) Phenobarbital indirectly activates the constitutive active androstane receptor (CAR) by inhibition of epidermal growth factor receptor signaling. Sci Signal 6:ra31

Nagy L and Schwabe JWR (2004) Mechanism of the nuclear receptor molecular switch. Trends Biochem Sci 29:317-324.

Nakamura K, Moore R, Negishi M, and Sueyoshi T (2007) Nuclear pregnane X receptor cross-talk with FoxA2 to mediate drug-induced regulation of lipid metabolism in fasting mouse liver. J Biol Chem 282:9768-9776.

Oetjen LK, Trier AM, and Kim BS (2018) PXR: a new player in atopic dermatitis. J Invest Dermatol 138:8-10. 
Okuda Y, Kushida M, Sumida K, Nagahori H, Nakamura Y, Higuchi H, Kawamura S, Lake BG, Cohen SM, and Yamada T (2017) Editor's highlight: mode of action analysis for rat hepatocellular tumors produced by the synthetic pyrethroid momfluorothrin: evidence for activation of the constitutive androstane receptor and mitogenicity in rat hepatocytes. Toxicol Sci 158:412-430.

Oladimeji PO and Chen T (2018) PXR: more than just a master xenobiotic receptor. Mol Pharmacol 93:119-127.

Oladimeji PO, Lin W, Brewer CT, and Chen T (2017) Glucose-dependent regulation of pregnane X receptor is modulated by AMP-activated protein kinase. Sci Rep 7:46751.

Osabe M and Negishi M (2011) Active ERK1/2 protein interacts with the phosphorylated nuclear constitutive active/androstane receptor (CAR; NR1I3), repressing dephosphorylation and sequestering CAR in the cytoplasm. J Biol Chem 286:35763-35769.

Ouyang N, Ke S, Eagleton N, Xie Y, Chen G, Laffins B, Yao H, Zhou B, and Tian Y (2010) Pregnane $\mathrm{X}$ receptor suppresses proliferation and tumourigenicity of colon cancer cells. $\mathrm{Br} J$ Cancer 102: 1753-1761.

Park Y, Li H, and Kemper B (1996) Phenobarbital induction mediated by a distal CYP2B2 sequence in rat liver transiently transfected in situ. J Biol Chem 271:23725-23728.

Phillips JM, Yamamoto Y, Negishi M, Maronpot RR, and Goodman JI (2007) Orphan nuclear receptor constitutive active/androstane receptor-mediated alterations in DNA methylation during phenobarbital promotion of liver tumorigenesis. Toxicol Sci 96:72-82.

Polyzos SA, Kountouras J, Anastasilakis AD, Geladari EV, and Mantzoros CS (2014) Irisin in patients with nonalcoholic fatty liver disease. Metabolism 63:207-217.

Pondugula SR, Pavek P, and Mani S (2016) Pregnane X receptor and cancer: context-specificity is key. Nucl Receptor Res 3:101198.

Qatanani M and Moore DD (2005) CAR, the continuously advancing receptor, in drug metabolism and disease. Curr Drug Metab 6:329-339.

Qatanani M, Zhang J, and Moore DD (2005) Role of the constitutive androstane receptor in xenobiotic-induced thyroid hormone metabolism. Endocrinology 146:995-1002.

Robbins D, Bakke J, Cherian MT, Wu J, and Chen T (2016) PXR interaction with p53: a meeting of two masters. Cell Death Dis 7:e2218.

Roman ÁC, Carvajal-Gonzalez JM, Merino JM, Mulero-Navarro S, and Fernández-Salguero PM (2018) The aryl hydrocarbon receptor in the crossroad of signalling networks with therapeutic value. Pharmacol Ther 185:50-63.

Romeo S, Kozlitina J, Xing C, Pertsemlidis A, Cox D, Pennacchio LA, Boerwinkle E, Cohen JC, and Hobbs HH (2008) Genetic variation in PNPLA3 confers susceptibility to nonalcoholic fatty liver disease. Nat Genet 40:1461-1465.

Rysä J, Buler M, Savolainen MJ, Ruskoaho H, Hakkola J, and Hukkanen J (2013) Pregnane X receptor agonists impair postprandial glucose tolerance. Clin Pharmacol Ther 93:556-563.

Shizu R, Benoki S, Numakura Y, Kodama S, Miyata M, Yamazoe Y, and Yoshinari K (2013) Xenobiotic-induced hepatocyte proliferation associated with constitutive active/androstane receptor (CAR) or peroxisome proliferator-activated receptor $\alpha(\operatorname{PPAR} \alpha)$ is enhanced by pregnane $\mathrm{X}$ receptor (PXR) activation in mice. PLoS One 8:e61802.

Shizu R, Osabe M, Perera L, Moore R, Sueyoshi T, and Negishi M (2017) Phosphorylated nuclear receptor CAR forms a homodimer to repress its constitutive activity for ligand activation. $M o$ Cell Biol 37:e0649-16.

Shizu R, Shindo S, Yoshida T, and Numazawa S (2012) MicroRNA-122 down-regulation is involved in phenobarbital-mediated activation of the constitutive androstane receptor. PLoS One 7:e41291.

Smagris E, BasuRay S, Li J, Huang Y, Lai KM, Gromada J, Cohen JC, and Hobbs HH (2015) Pnpla3I148M knockin mice accumulate PNPLA3 on lipid droplets and develop hepatic steatosis. Hepatology 61:108-118.

Soldatow V, Peffer RC, Trask OJ, Cowie DE, Andersen ME, LeCluyse E, and Deisenroth C (2016) Development of an in vitro high content imaging assay for quantitative assessment of CAR dependent mouse, rat, and human primary hepatocyte proliferation. Toxicol In Vitro 36:224-237.

Sonoda J, Pei L, and Evans RM (2008) Nuclear receptors: decoding metabolic disease. FEBS Lett 582:2-9.

Squires EJ, Sueyoshi T, and Negishi M (2004) Cytoplasmic localization of pregnane X receptor and ligand-dependent nuclear translocation in mouse liver. J Biol Chem 279:49307-49314.

Staudinger JL, Woody S, Sun M, and Cui W (2013) Nuclear-receptor-mediated regulation of drug and bile-acid-transporter proteins in gut and liver. Drug Metab Rev 45:48-59.

Sueyoshi T, Kawamoto T, Zelko I, Honkakoski P, and Negishi M (1999) The repressed nuclear receptor CAR responds to phenobarbital in activating the human CYP2B6 gene. J Biol Chem 274:6043-6046.

Sueyoshi T and Negishi M (2001) Phenobarbital response elements of cytochrome P450 genes and nuclear receptors. Аппи Rev Pharmacol Toxicol 41:123-143.

Takasu N, Yamada T, Miura H, Sakamoto S, Korenaga M, Nakajima K, and Kanayama M (1982) Rifampicin-induced early phase hyperglycemia in humans. Am Rev Respir Dis 125:23-27.

Takwi AA, Wang YM, Wu J, Michaelis M, Cinatl J, and Chen T (2014) miR-137 regulates the constitutive androstane receptor and modulates doxorubicin sensitivity in parental and doxorubicin-resistant neuroblastoma cells. Oncogene 33:3717-3729.

Tamura K, Inoue K, Takahashi M, Matsuo S, Irie K, Kodama Y, Gamo T, Ozawa S, and Yoshida M (2015) Involvement of constitutive androstane receptor in liver hypertrophy and liver tumor development induced by triazole fungicides. Food Chem Toxicol 78:86-95.

Tamura K, Inoue K, Takahashi M, Matsuo S, Kodama Y, and Yoshida M (2016) A crucial role of constitutive androstane receptor (CAR) in liver tumor development by imazalil in mice. J Toxicol Sci 41:801-811.

Tanner N, Kubik L, Luckert C, Thomas M, Hofmann U, Zanger UM, Böhmert L, Lampen A, and Braeuning A (2018) Regulation of drug metabolism by the interplay of inflammatory signaling, steatosis, and xeno-sensing receptors in HepaRG cells. Drug Metab Dispos 46: 326-335.

Terc J, Hansen A, Alston L, and Hirota SA (2014) Pregnane X receptor agonists enhance intestinal epithelial wound healing and repair of the intestinal barrier following the induction of experimental colitis. Eur J Pharm Sci 55:12-19.
Timsit YE and Negishi M (2007) CAR and PXR: the xenobiotic-sensing receptors. Steroids 72: 231-246.

Tolson AH and Wang H (2010) Regulation of drug-metabolizing enzymes by xenobiotic receptors: PXR and CAR. Adv Drug Deliv Rev 62:1238-1249.

Trottier E, Belzil A, Stoltz C, and Anderson A (1995) Localization of a phenobarbital-responsive element (PBRE) in the 5'-flanking region of the rat CYP2B2 gene. Gene 158:263-268.

Tschuor C, Kachaylo E, Limani P, Raptis DA, Linecker M, Tian Y, Herrmann U, Grabliauskaite K, Weber A, Columbano A, et al. (2016) Constitutive androstane receptor (Car)-driven regeneration protects liver from failure following tissue loss. J Hepatol 65:66-74.

Ueda A, Hamadeh HK, Webb HK, Yamamoto Y, Sueyoshi T, Afshari CA, Lehmann JM, and Negishi M (2002) Diverse roles of the nuclear orphan receptor CAR in regulating hepatic genes in response to phenobarbital. Mol Pharmacol 61:1-6.

Wagner M, Halilbasic E, Marschall HU, Zollner G, Fickert P, Langner C, Zatloukal K, Denk H, and Trauner M (2005) CAR and PXR agonists stimulate hepatic bile acid and bilirubin detoxification and elimination pathways in mice. Hepatology 42:420-430.

Wang H and LeCluyse EL (2003) Role of orphan nuclear receptors in the regulation of drugmetabolising enzymes. Clin Pharmacokinet 42:1331-1357.

Wang H, Venkatesh M, Li H, Goetz R, Mukherjee S, Biswas A, Zhu L, Kaubisch A, Wang L, Pullman J, et al. (2011) Pregnane X receptor activation induces FGF19-dependent tumor aggressiveness in humans and mice. $J$ Clin Invest 121:3220-3232.

Wang YM, Ong SS, Chai SC, and Chen T (2012) Role of CAR and PXR in xenobiotic sensing and metabolism. Expert Opin Drug Metab Toxicol 8:803-817.

Wang Z, Li X, Wu Q, Lamb JC, IV, and Klaunig JE (2017) Toxaphene-induced mouse live tumorigenesis is mediated by the constitutive androstane receptor. J Appl Toxicol 37:967-975.

Watkins RE, Wisely GB, Moore LB, Collins JL, Lambert MH, Williams SP, Willson TM, Kliewer SA, and Redinbo MR (2001) The human nuclear xenobiotic receptor PXR: structural determinants of directed promiscuity. Science 292:2329-2333.

Wei P, Zhang J, Egan-Hafley M, Liang S, and Moore DD (2000) The nuclear receptor CAR mediates specific xenobiotic induction of drug metabolism. Nature 407:920-923.

Xie W, Barwick JL, Simon CM, Pierce AM, Safe S, Blumberg B, Guzelian PS, and Evans RM (2000) Reciprocal activation of xenobiotic response genes by nuclear receptors SXR/PXR and CAR. Genes Dev 14:3014-3023.

Yamada T, Okuda Y, Kushida M, Sumida K, Takeuchi H, Nagahori H, Fukuda T, Lake BG, Cohen SM, and Kawamura S (2014) Human hepatocytes support the hypertrophic but not the hyperplastic response to the murine nongenotoxic hepatocarcinogen sodium phenobarbital in an in vivo study using a chimeric mouse with humanized liver. Toxicol Sci 142:137-157.

Yamamoto Y, Kawamoto T, and Negishi M (2003) The role of the nuclear receptor CAR as a coordinate regulator of hepatic gene expression in defense against chemical toxicity. Arch Biochem Biophys 409:207-211.

Yamamoto Y, Moore R, Flavell RA, Lu B, and Negishi M (2010) Nuclear receptor CAR represses TNF $\alpha$-induced cell death by interacting with the anti-apoptotic GADD45B. PLoS One 5:e10121

Yamamoto Y, Moore R, Goldsworthy TL, Negishi M, and Maronpot RR (2004) The orphan nuclear receptor constitutive active/androstane receptor is essential for liver tumor promotion by phenobarbital in mice. Cancer Res 64:7197-7200.

Yan J, Chen B, Lu J, and Xie W (2015) Deciphering the roles of the constitutive androstane receptor in energy metabolism. Acta Pharmacol Sin 36:62-70.

Yang H, Garzel B, Heyward S, Moeller T, Shapiro P, and Wang H (2014) Metformin represses drug-induced expression of CYP2B6 by modulating the constitutive androstane receptor signaling. Mol Pharmacol 85:249-260.

Yoshinari K, Sueyoshi T, Moore R, and Negishi M (2001) Nuclear receptor CAR as a regulatory factor for the sexually dimorphic induction of $C Y B 2 B 1$ gene by phenobarbital in rat livers. $M o$ Pharmacol 59:278-284.

Yu L, Wang Z, Huang M, Li Y, Zeng K, Lei J, Hu H, Chen B, Lu J, Xie W, et al. (2016) Evodia alkaloids suppress gluconeogenesis and lipogenesis by activating the constitutive androstane receptor. Biochim Biophys Acta 1859:1100-1111.

Zanger UM, Turpeinen M, Klein K, and Schwab M (2008) Functional pharmacogenetics/genomics of human cytochromes P450 involved in drug biotransformation. Anal Bioanal Chem 392: 1093-1108.

Zelko I, Sueyoshi T, Kawamoto T, Moore R, and Negishi M (2001) The peptide near the C terminus regulates receptor CAR nuclear translocation induced by xenochemicals in mouse liver. Mol Cell Biol 21:2838-2846.

Zhang HJ, Zhang XF, Ma ZM, Pan LL, Chen Z, Han HW, Han CK, Zhuang XJ, Lu Y, Li XJ, et al. (2013) Irisin is inversely associated with intrahepatic triglyceride contents in obese adults. $J$ Hepatol 59:557-562.

Zhou J, Liu M, Zhai Y, and Xie W (2008) The antiapoptotic role of pregnane X receptor in human colon cancer cells. Mol Endocrinol 22:868-880.

Zhou J, Zhai Y, Mu Y, Gong H, Uppal H, Toma D, Ren S, Evans RM, and Xie W (2006) A nove pregnane $\mathrm{X}$ receptor-mediated and sterol regulatory element-binding protein-independent lipogenic pathway. J Biol Chem 281:15013-15020.

Zhuo W, Hu L, Lv J, Wang H, Zhou H, and Fan L (2014) Role of pregnane X receptor in chemotherapeutic treatment. Cancer Chemother Pharmacol 74:217-227.

Zucchini N, de Sousa G, Bailly-Maitre B, Gugenheim J, Bars R, Lemaire G, and Rahmani R (2005) Regulation of Bcl-2 and Bcl-xL anti-apoptotic protein expression by nuclear receptor PXR in primary cultures of human and rat hepatocytes. Biochim Biophys Acta 1745:48-58.

Address correspondence to: Dr. Hongbing Wang, Department of Pharmaceutical Sciences, University of Maryland School of Pharmacy, 20 Penn Street, Baltimore, MD 21201. E-mail: hongbing.wang@rx.umaryland.edu 